\title{
Radiographic Progression Inhibition with Intravenous Golimumab in Psoriatic Arthritis: Week 24 Results of a Phase III, Randomized, Double-blind, Placebo-controlled Trial
}

\author{
Arthur Kavanaugh, M. Elaine Husni, Diane D. Harrison, Lilianne Kim, Kim Hung Lo, \\ Lenore Noonan, and Elizabeth C. Hsia
}

\begin{abstract}
Objective. Evaluate effects of intravenous (IV) golimumab (GOL) on radiographic progression in psoriatic arthritis (PsA).

Methods. This phase III, randomized, double-blind, placebo-controlled trial (GO-VIBRANT) randomized patients with active PsA to receive IV placebo $(\mathrm{n}=239)$ or IV GOL $2 \mathrm{mg} / \mathrm{kg}(\mathrm{n}=241)$ at weeks $0,4,12$, and 20. Radiographic progression (controlled secondary endpoint) was evaluated as change from baseline at Week 24 in PsA-modified total Sharp/van der Heijde scores (SvdH). The proportions of patients with a change from baseline at Week 24 in the total PsA-modified SvdH exceeding the smallest detectable change (SDC) or $>0$ or 0.5 also were determined.

Results. Overall, 474 patients (237/arm) contributed radiographic data. Results obtained from the 2 blinded, independent radiographic readers demonstrated good agreement (total score intraclass correlation coefficients: baseline $=0.93$, Week $24=0.92$, Week 24 change score $=0.73$ ). GOL demonstrated significant inhibition of radiographic progression relative to placebo from baseline to Week 24 (mean changes in PsA-modified total SvdH: -0.36 vs 1.95 ; treatment difference: $-2.32 ; \mathrm{p}<0.001$ ). At Week 24, smaller proportions of GOL- versus placebo-treated patients demonstrated an increase in the total PsA-modified SvdH score exceeding the SDC (8.0\% vs $27.0 \%$, respectively; difference: $-19.0 \%$; $\mathrm{p}<0.001)$, > 0 (28.3\% vs $57.0 \%$, respectively; difference: $-28.7 \%$; p < 0.001$)$, or $>0.5(18.6 \%$ vs $41.8 \%$, respectively; difference: $-23.2 \%$; $<<0.001)$. Results were consistent for erosion and joint space narrowing scores, in hands and feet, and in patients with/without baseline concomitant methotrexate use. Prevention of radiographic progression by GOL was independent of clinical response.

Conclusion. IV GOL is significantly better than placebo in inhibiting radiographic progression of structural damage in active PsA. [Clinical trial registration number (www.ClinicalTrials.gov): NCT02181673] (First Release February 15 2019; J Rheumatol 2019;46:595-602; doi:10.3899/ jrheum.180681)
\end{abstract}

Key Indexing Terms:

PSORIATIC ARTHRITIS

TUMOR NECROSIS FACTOR INHIBITORS

RADIOGRAPHY DISEASE ACTIVITY

From Internal Medicine - Rheumatology, University of California at San Diego, La Jolla, California; Department of Internal Medicine Rheumatology, Cleveland Clinic, Cleveland, Ohio; Immunology, Janssen Research \& Development LLC, Spring House, Pennsylvania; Rheumatology, University of Pennsylvania, Philadelphia, Pennsylvania, USA

Janssen Research \& Development LLC funded this study. Janssen Biotech Inc., part of the Janssen Pharmaceutical Companies of Johnson \& Johnson, manufactures golimumab. Authors who are employees of the study sponsor were involved in the study design, collecting and analyzing the data, and interpreting the results. Writing support was provided by Janssen Scientific Affairs LLC. Janssen Research \& Development LLC approved the content of the article; the authors made the decision to submit for publication.

Drs. Harrison and Hsia, and L. Kim, K.H. Lo, and L. Noonan are employees of Janssen Research \& Development LLC and own stock or stock options in Johnson \& Johnson, of which Janssen Research \& Development LLC is a wholly owned subsidiary.

A. Kavanaugh, MD, Internal Medicine - Rheumatology, University of California at San Diego; M.E. Husni, MD, MPH, Internal Medicine Rheumatology, Cleveland Clinic; D.D. Harrison, MD, MPH, Immunology,
Janssen Research \& Development LLC; L. Kim, PhD, Immunology, Janssen Research \& Development LLC; K.H. Lo, PhD, Immunology, Janssen Research \& Development LLC; L. Noonan, RT(MR), Immunology, Janssen Research \& Development LLC; E.C. Hsia, MD, MSCE, Immunology, Janssen Research \& Development LLC, and Rheumatology, University of Pennsylvania.

Address correspondence to Dr. E.C. Hsia, Janssen Research \& Development LLC, 1400 McKean Road, PO Box 776, Spring House, Pennsylvania 19477,USA.E-mail: ehsia@its.jnj.com

Full Release Article. For details see Reprints and Permissions at jrheum.org

Accepted for publication October 18, 2018.

Psoriatic arthritis (PsA) is a chronic, inflammatory arthropathy that can affect the peripheral joints, axial skeleton, sacroiliac joints, and entheses, and is also associated with dactylitis and psoriatic nail and skin disease ${ }^{1}$. More than half of patients with PsA have radiographic evidence of erosions, and up to $40 \%$ of patients develop severe erosive arthropathy ${ }^{1,2}$.

Personal non-commercial use only. The Journal of Rheumatology Copyright @ 2019. All rights reserved. 
The advent of biologic therapies that inhibit the activity of proinflammatory cytokines such as tumor necrosis factor- $\alpha$ (TNF- $\alpha$ ) has significantly improved the ability to effectively treat many aspects of PsA ${ }^{3,4}$. Inhibition of TNF- $\alpha$ has been shown to induce rapid and significant improvement of arthritis and psoriasis in patients with active PsA while maintaining an acceptable safety profile ${ }^{5}$.

Golimumab (GOL) is a human TNF- $\alpha$ monoclonal antibody that is approved for the treatment of rheumatoid arthritis (RA), ankylosing spondylitis, and $\mathrm{Ps}^{6}$. GOL is the only anti-TNF therapy with both subcutaneous (SC) and intravenous (IV) formulations. SC GOL $50 \mathrm{mg}$ demonstrated longterm clinical efficacy and inhibition of structural damage in the phase III GO-REVEAL trial of patients with moderate to severe $\mathrm{PsA}^{7,8}$. More recently, in the phase III GO-VIBRANT study of IV GOL in PsA, patients receiving IV GOL $2 \mathrm{mg} / \mathrm{kg}$ through 24 weeks had significantly greater improvements in PsA signs and symptoms and significantly less radiographic progression versus placebo-treated patients ${ }^{9}$. Given the importance of addressing radiographic damage in patients with PsA, this report provides greater clarity on radiographic findings from the large cohort of patients from the GO-VIBRANT GOL trial.

\section{MATERIALS AND METHODS}

Study conduct. GO-VIBRANT (Clinicaltrials.gov identifier: NCT02181673) was conducted according to the Declaration of Helsinki and Good Clinical Practice guidelines. Governing ethical bodies approved the study protocol, and patients provided written informed consent. Schulman IRB (now Advarra) provided centralized approvals for sites in the United States (reference no. 201404246) and Canada (reference no. 201404730).

Patients. Eligibility criteria for GO-VIBRANT have been published previously $^{9}$. Briefly, participants were adults ( $\geq 18$ yrs) with PsA for $\geq 6$ months who met the ClASsification for Psoriatic ARthritis (CASPAR) criteria ${ }^{10}$ at screening. Patients had active PsA, defined as $\geq 5$ of 66 swollen joints and $\geq 5$ of 68 tender joints at screening and baseline, and high-sensitivity C-reactive protein $(\mathrm{CRP}) \geq 0.6 \mathrm{mg} / \mathrm{dl}$ at screening, despite current or previous disease-modifying antirheumatic drugs $(\geq 3 \mathrm{mos})$ and/or nonsteroidal antiinflammatory drugs (NSAID; $\geq 4$ weeks) or demonstrated intolerance to these agents.

Participants could not have previously received biologic therapy. Continued stable use of methotrexate (MTX; $\leq 25 \mathrm{mg} /$ week), low-dose oral corticosteroids ( $\leq 10 \mathrm{mg}$ prednisone/day), and NSAID (usual approved marketed doses) was permitted as previously described ${ }^{9}$.

Randomization and blinding. Patient assignment to study treatment was accomplished with permuted block randomization (in a 1:1 ratio) stratified by geographic region and baseline MTX use through an interactive Webbased response system. Patients and investigators were blinded to treatment group assignment.

Study design. In the phase III, multicenter, randomized, double-blind, placebo-controlled GO-VIBRANT trial, patients received IV infusions over $30 \pm 10 \mathrm{~min}$ of either placebo or GOL $2 \mathrm{mg} / \mathrm{kg}$ at weeks $0,4,12$, and 20 . Study visits were scheduled every $2-4$ weeks through Week 24 . Patients in either treatment group who demonstrated $<5 \%$ improvement in swollen and tender joint counts at Week 16 entered early escape, in which they were allowed one of the following changes to the standard-of-care, nonbiologic rescue medications at the discretion of the investigator: (1) increase in dose or initiation of low-dose corticosteroids $(\leq 10 \mathrm{mg} /$ day prednisone or equivalent), MTX ( $\leq 25 \mathrm{mg} /$ week), or NSAID; or (2) initiation of sulfasalazine
( $\leq 3 \mathrm{~g} /$ day), hydroxychloroquine $(\leq 400 \mathrm{mg} /$ day $)$, or leflunomide $(\leq 20$ $\mathrm{mg} /$ day).

Radiographic assessments. Single radiographs of the hands (posteroanterior) and feet (anteroposterior) were obtained at weeks 0 and 24 (or at the end of study if the patient discontinued prior to Week 24). They were read by 2 independent readers (and a third independent reader as an adjudicator in cases of a > 10-unit difference in total change score between readers or a missing total change score from one of the 2 primary readers) who were blinded to patient identity, treatment group, and assessment timepoint. Patients who entered early escape also had radiographs obtained at Week 16. Changes in radiographic damage were measured using the total Sharp/van der Heijde score (SvdH) with modifications for patients with PsA (i.e., inclusion of distal interphalangeal joints in the hands and pencil-in-cup and gross osteolysis deformities) ${ }^{11,12}$.

The total PsA-modified $\mathrm{SvdH}^{11,12}$ ranges from 0-528. It sums the erosion (0-320) and joint space narrowing (JSN; 0-208) scores for 40 and 12 joints of the hands and feet, respectively. For erosion severity, the surface area involved is scored from 0 (no erosion) to 5 (extensive loss of bone from more than half of the articulating bone). Both sides of foot joints are graded, yielding a maximum erosion score of 10 per foot joint. Severity of JSN is scored from 0 (no JSN) to 4 (complete loss of joint space, bony ankylosis, or complete luxation). Thus, higher scores and more positive change scores indicate more radiographic damage and more radiographic progression, respectively.

Statistical analysis. Change from baseline at Week 24 in the total PsA-modified SvdH was one of 4 major secondary study endpoints. Additional predefined radiographic endpoints included the following: (1) the proportions of patients and joints with no new erosion or no new JSN (among patients with $\geq 1$ joint with a score of 0 at baseline and a corresponding non-missing score at the timepoint evaluated); (2) the proportions of patients with a change from baseline at Week 24 in the PsA-modified $\mathrm{SvdH}$ score $>0$ or $>0.5$; and (3) the proportion of patients with a change from baseline at Week 24 in the total PsA-modified SvdH score greater than its smallest detectable change (SDC).

To assess agreement between the 2 primary independent readers, changes from baseline at Week 24 in the PsA-modified SvdH total, erosion, and JSN scores were summarized by reader, and intraclass correlation (ICC) coefficients were determined for intrareader and interreader variability; ICC coefficients represented the percent of the total correlation within each patient's variation between the 2 readers. Pencil-in-cup or gross osteolysis deformity assessments also were compared between readers.

The change in the total PsA-modified SvdH was evaluated for randomized patients who were treated and had a non-missing baseline score (full analysis set for structural damage analyses), representing a modified intent-to-treat analysis. Using data from patients contributing radiographic data at both Week 0 and Week 24 for the major secondary endpoint, multiple imputation methodology ${ }^{13}$ was used to impute Week 24 radiograph scores for patients with missing data and/or who early escaped at Week 16 . Specifically, the linear regression imputation model was built using data from patients with baseline and Week $24 \mathrm{SvdH}$ and included change from baseline to Week 24 in $\mathrm{SvdH}$ as the dependent variable and as covariates baseline SvdH, natural logarithm (CRP + 1), baseline MTX use (yes, no), and randomized treatment group. The model was fitted to derive the distribution of the coefficients, which was then used to predict the missing value.

Planned sensitivity analyses of the change in the total PsA-modified SvdH from baseline at Week 24 were conducted to evaluate alternative methods of handling missing data, including an ANOVA model on the van der Waerden normal scores with missing data imputed through linear extrapolation. The same ANOVA model was modified to exclude patients with missing Week 24 data (i.e., observed data only), to use linear extrapolation for Week 24 scores for all patients who early escaped at Week 16 and for missing data, and to use the last observation carried forward (LOCF) to impute Week 24 scores for all patients with missing Week 24 scores. A tipping point analysis with multiple imputation methodology was used to evaluate the deviation from missing-at-random assumptions for missing data.

Personal non-commercial use only. The Journal of Rheumatology Copyright $\odot$ (2019. All rights reserved 
In a posthoc evaluation, change in the total PsA-modified SvdH at Week 24 was compared between patients who did and did not achieve clinical response, defined by $\geq 20 \%, 50 \%$, or $70 \%$ improvement in the American College of Rheumatology response criteria (ACR20, ACR50, ACR70, respectively) ${ }^{14}$, at Week 24 . For radiographic endpoints other than the study's major secondary endpoint, treatment group differences were analyzed using ANCOVA on the van der Waerden normal scores for continuous endpoints (missing data imputed by linear extrapolation) and Cochran-Mantel-Haenszel testing for dichotomous endpoints.

All statistical tests were stratified by baseline MTX use (yes, no) where feasible and performed at an $\alpha$ level of 0.05 (2-sided). A sample size of about 220 patients per treatment arm was estimated a priori to provide $90.7 \%$ power in detecting a significant treatment group difference in the mean change in total PsA-modified SvdH from baseline at Week 24.

\section{RESULTS}

Patient disposition and baseline characteristics. Patient disposition through Week 24 of GO-VIBRANT has been reported $^{9}$. Briefly, data were collected from September 2014 to July 2016 at 90 sites in 11 European and North American countries. Among the 817 screened patients, 480 were randomized to IV placebo $(\mathrm{n}=239)$ or IV GOL $2 \mathrm{mg} / \mathrm{kg}(\mathrm{n}$ $=241$ ). In total, 474 patients contributed data to structural damage analyses, including 237 patients each in the placebo and GOL groups with observed data at baseline and 215 and 231 patients, respectively, with observed data at Week 24.

Demographic and disease characteristics were generally well-balanced between the treatment groups, including baseline radiographic findings (Table 1).

Reader agreement. Individual reader assessments of the change from baseline at Week 24 in the total PsA-modified $\mathrm{SvdH}$, as well as in its component scores, were consistent with each other. For baseline and Week 24 PsA-modified SvdH, ICC coefficients for total (0.93 and 0.92, respectively), erosion (both 0.87 ), and JSN (both 0.96 ) scores indicated

Table 1. Baseline demographic and disease characteristics.

\begin{tabular}{lcc}
\hline Characteristics & IV Placebo & $\begin{array}{c}\text { IV Golimumab, } \\
2 \mathrm{mg} / \mathrm{kg}\end{array}$ \\
\hline Patients randomized, $\mathrm{n}$ & & 241 \\
Age, yrs & 239 & $45.7 \pm 11.3$ \\
Male & $46.7 \pm 12.5$ & $128(53.1)$ \\
Duration of PsA, yrs & $121(50.6)$ & $6.2 \pm 6.0$ \\
Swollen joint count (0-66) & $5.3 \pm 5.9$ & $14.0 \pm 8.4$ \\
Tender joint count (0-68) & $14.1 \pm 8.2$ & $25.1 \pm 13.8$ \\
CRP, mg/dl & $26.1 \pm 14.4$ & $237(98.3)$ \\
PsA-modified SvdH & $2.0 \pm 2.1$ & $35.5 \pm 55.2$ \\
$\quad$ Total (0-528) & $237(99.2)$ & $22.2 \pm 31.7$ \\
$\quad$ Erosion (0-320) & $34.5 \pm 53.5$ & $13.2 \pm 24.8$ \\
$\quad$ JSN (0-208) & $21.1 \pm 30.2$ & $163(67.6)$ \\
Concomitant MTX & $13.3 \pm 24.3$ & $14.8 \pm 4.7$ \\
$\quad$ Dose, mg/week & $173(72.4)$ & $169(70.1)$ \\
Concomitant NSAID & $14.9 \pm 4.8$ & $65(27.0)$ \\
Concomitant oral corticosteroids & $165(69.0)$ & \\
\hline
\end{tabular}

Data are presented as $\mathrm{n}(\%)$ or mean \pm SD. CRP: C-reactive protein; IV: intravenous; JSN: joint space narrowing; MTX: methotrexate; PsA: psoriatic arthritis; NSAID: nonsteroidal antiinflammatory drugs; SvdH: Sharp/van der Heijde score. good agreement. For Week 24 change scores, the ICC coefficients were $0.73,0.64$, and 0.72 for total, erosion, and JSN scores, respectively. Across treatment groups, Reader 1 identified fewer patients with pencil-in-cup or gross osteolysis deformities than did Reader 2 at both baseline (13 vs 43 patients) and Week 24 (14 vs 45 patients). While Reader 1 generally read less damage than Reader 2, each reader was internally consistent, and changes from baseline were consistent between readers (also see Supplementary Table 1, available with the online version of this article).

PsA-modified SvdH through Week 24. Patients who received IV GOL $2 \mathrm{mg} / \mathrm{kg}$ exhibited significantly less radiographic progression than did placebo-treated patients (i.e., the respective mean changes from baseline at Week 24 in the PsA-modified SvdH were -0.36 vs 1.95 , with a treatment difference of $-2.32 ; \mathrm{p}<0.001$; Table 2). The cumulative probability plot for total PsA-modified SvdH (Figure 1A) demonstrated clear separation between treatment groups, with greater inhibition of progression and fewer patients with progression among GOL- than placebo-treated patients.

Results obtained from 5 planned sensitivity analyses (all $\mathrm{p}<0.001$ ) were consistent and supported the efficacy of IV GOL in inhibiting radiographic progression. Specifically, patients who received IV GOL $2 \mathrm{mg} / \mathrm{kg}$ exhibited significantly less radiographic progression than placebo-treated patients from baseline to Week 24 when evaluated with an ANOVA model on the van der Waerden normal scores using linear extrapolation to impute missing data (respective mean changes in SvdH: -0.38 vs 1.88; p < 0.001) and with the same ANOVA model but using only observed data ( -0.39 vs 2.08 ; $\mathrm{p}<0.001)$, linear extrapolation for Week 24 scores for all patients who early escaped at Week 16 and for missing data $(-0.37$ vs $1.79 ; \mathrm{p}<0.001)$, and LOCF methodology to impute Week 24 scores for all patients with missing Week 24 scores $(-0.38$ vs $1.88 ; \mathrm{p}<0.001)$. In a tipping point analysis, $\mathrm{p}$ values derived by pooling over 100 imputed samples using the standard error of the estimated difference for each combination of treatment shifts for imputed missing values were all $<0.001$.

Additionally, subgroup analyses based on baseline demographics, disease characteristics, and concomitant therapy were consistent in favoring IV GOL over placebo in inhibiting radiographic progression. These variables included sex (male, female); age ( $<65, \geq 65 \mathrm{yrs})$; body mass index $\left(<25, \geq 25\right.$ to $\left.<30, \geq 30 \mathrm{mg} / \mathrm{kg}^{2}\right)$; PsA duration $(<1, \geq 1$ to $<3, \geq 3 \mathrm{yrs}$ ); baseline numbers of swollen or tender joints ( $\geq 5$ to $<10, \geq 10$ to $<15, \geq 15)$; baseline CRP $(<1, \geq 1$ $\mathrm{mg} / \mathrm{dl}$ ); and baseline use (yes, no) of MTX (Figures 1B and 1C, Table 2), NSAID (Supplementary Figures 1A and 1B, available with the online version of this article; Table 2), and oral low-dose corticosteroids (Supplementary Figures 1C and 1D, available with the online version of this article; Table 2). Results also were consistent for component erosion and JSN scores, and for hands and feet (Table 2).

Personal non-commercial use only. The Journal of Rheumatology Copyright (c) 2019. All rights reserved. 
Table 2. Summary of change from baseline at Week 24 in PsA-modified SvdH (full analysis set for structural damage endpoints).

\begin{tabular}{|c|c|c|}
\hline Variables & $\begin{array}{l}\text { IV Placebo, } \\
\mathrm{n}=237\end{array}$ & $\begin{array}{l}\text { IV Golimumab, } 2 \mathrm{mg} / \mathrm{kg} \text {, } \\
\qquad \mathrm{n}=237\end{array}$ \\
\hline Change in total PsA-modified $\mathrm{SvdH}^{\mathrm{a}}$, mean (SD) & $1.95(0.26)$ & $-0.36(0.14)$ \\
\hline Estimated mean $(95 \% \mathrm{CI})$ & $1.95(1.40-2.51)$ & $-0.36(-0.66$ to -0.07$)$ \\
\hline Estimated mean difference (SE) & & $-2.32(0.32)$ \\
\hline $\mathrm{p}^{\mathrm{b}}$ & & $<0.001$ \\
\hline \multicolumn{3}{|l|}{ Change in total PsA-modified $\mathrm{SvdH}^{\mathrm{a}}$, mean (SD), by: } \\
\hline $\begin{array}{l}\text { MTX use at baseline } \\
\mathrm{p}^{\mathrm{b}}\end{array}$ & $2.14(4.14)$ & $\begin{array}{l}-0.36(1.91) \\
\quad<0.001\end{array}$ \\
\hline No MTX use at baseline & $1.58(3.84)$ & $-0.36(2.77)$ \\
\hline $\mathrm{p}^{\mathrm{b}}$ & & 0.001 \\
\hline NSAID use at baseline & $2.16(3.92)$ & $-0.57(2.13)$ \\
\hline Posthoc $\mathrm{p}^{\mathrm{b}}$ & & $<0.001$ \\
\hline No NSAID use at baseline & $1.48(4.35)$ & $0.18(2.37)$ \\
\hline Posthoc $\mathrm{p}^{\mathrm{b}}$ & & 0.037 \\
\hline Oral corticosteroid use at baseline & $1.17(2.50)$ & $0.11(2.59)$ \\
\hline Posthoc $\mathrm{p}^{\mathrm{b}}$ & & 0.029 \\
\hline No oral corticosteroid use at baseline & $2.27(4.49)$ & $-0.53(2.05)$ \\
\hline Posthoc $\mathrm{p}^{\mathrm{b}}$ & & $<0.001$ \\
\hline Change in total hand PsA-modified SvdH, mean (SD) & $1.22(3.07)$ & $-0.36(1.67)$ \\
\hline Change in total feet PsA-modified SvdH, mean (SD) & $0.66(1.80)$ & $-0.02(1.08)$ \\
\hline Change in erosion score, ${ }^{\mathrm{c}}$ mean $(\mathrm{SD})$ & $1.27(2.81)$ & $-0.29(1.74)$ \\
\hline $\mathrm{p}^{\mathrm{d}}$ & & $<0.001$ \\
\hline Change in JSN score, ${ }^{\mathrm{c}}$ mean (SD) & $0.61(1.67)$ & $-0.08(1.09)$ \\
\hline $\mathrm{p}^{\mathrm{d}}$ & & $<0.001$ \\
\hline Patients with $\geq 1$ joint with erosion score $=0$ at baseline $\mathrm{e}^{\mathrm{e}}$ & 213 & 230 \\
\hline $\begin{array}{l}\text { Patients with no new erosions at Week } 24 \text { in joints with } \\
\text { erosion score }=0 \text { at baseline, } \mathrm{n}(\%)\end{array}$ & $115(54.0)$ & $171(74.3)$ \\
\hline$\%$ difference $(95 \% \mathrm{CI})^{\mathrm{f}}$ & & $20.3(11.52-29.02)$ \\
\hline $\mathrm{p}^{\mathrm{g}}$ & & $<0.001$ \\
\hline Patients with $\geq 1$ joint with JSN score $=0$ at baseline $\mathrm{e}^{\mathrm{e}}$ & 214 & 229 \\
\hline $\begin{array}{l}\text { Patients with no new JSN at Week } 24 \text { in joints with JSN } \\
\text { score }=0 \text { at baseline, } \mathrm{n}(\%)\end{array}$ & $162(75.7)$ & $205(89.5)$ \\
\hline$\%$ difference $(95 \% \mathrm{CI})^{\mathrm{f}}$ & & $13.7(6.74-20.65)$ \\
\hline $\mathrm{p}^{\mathrm{g}}$ & & $<0.001$ \\
\hline
\end{tabular}

\footnotetext{
${ }^{\text {a }}$ Change from baseline in total PsA-modified SvdH based on imputed data using multiple imputation for missing data and using predictive mean matching method. Summary statistics calculated from patients with observed data and the average of the 100 imputations for each patient with missing data. ${ }^{b} \mathrm{P}$ value derived by pooling over 100 imputed samples using the standard error of the mean. ${ }^{c}$ Change from baseline in erosion and JSN scores based on imputed data using linear extrapolation for missing data. ${ }^{\mathrm{d}} \mathrm{P}$ values based on ANCOVA on the van der Waerden scores, controlling for baseline MTX usage (yes, no). ${ }^{\mathrm{e}}$ Erosion and JSN scores are based on observed values. Only patients with $\geq 1$ joint with a score $=0$ at baseline and $\geq 1$ corresponding non-missing score at Week 24 were included. ${ }^{\mathrm{f}}$ The $95 \%$ CI are based on Wald statistic controlling for baseline MTX usage (yes, no). ${ }^{\mathrm{g}} \mathrm{P}$ values are based on CMH test controlling for baseline MTX usage (yes, no). CMH: Cochran-Mantel-Haenszel; IV: intravenous; JSN: joint space narrowing; MTX: methotrexate; NSAID: nonsteroidal antiinflammatory drug; PsA: psoriatic arthritis; SE: standard error; SvdH: Sharp/van der Heijde Score.
}

Change in the total PsA-modified SvdH in ACR responders versus nonresponders at Week 24. Differences in mean changes in radiographic progression from baseline to Week 24 observed between GOL- and placebo-treated patients were evident in both Week 24 ACR20 responders $(-0.60$ vs 1.08 ; $\mathrm{p}<0.001)$ and nonresponders (0.41 vs 2.48; p < 0.001). Regardless of treatment arm, ACR20 clinical responders demonstrated, on average, numerically less radiographic progression than nonresponders (Table 3 ).

Prevention of new joint erosion and JSN. In patients with $\geq 1$ joint with an erosion score of 0 at baseline, a greater proportion of patients treated with IV GOL $2 \mathrm{mg} / \mathrm{kg}$ than with IV placebo showed no new erosion in those joints at Week $24(74.3 \%$ vs $54.0 \%$, respectively; difference of $20.3 \%$; $\mathrm{p}<0.001$; Figure 2). Similarly, in patients with $\geq 1$ joint with a JSN score $=0$ at baseline, a greater proportion of GOL- treated than placebo-treated patients showed no new JSN in those joints at Week $24(89.5 \%$ vs $75.7 \%$, respectively; difference of $13.8 \%$; $\mathrm{p}<0.001$; Figure 2).

Patients with radiographic progression. At Week 24, a smaller proportion of GOL- versus placebo-treated patients demonstrated radiographic progression based on an increase

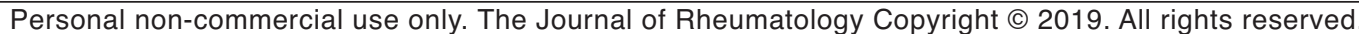


A

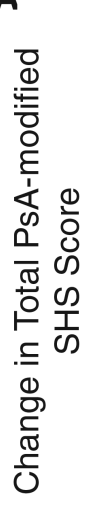

\section{All Patients}

$$
\begin{aligned}
& 30 \\
& 25 \\
& 20 \\
& 15 \\
& 10
\end{aligned}-
$$$$
20-
$$

$5-1$

$S D C=2.49$

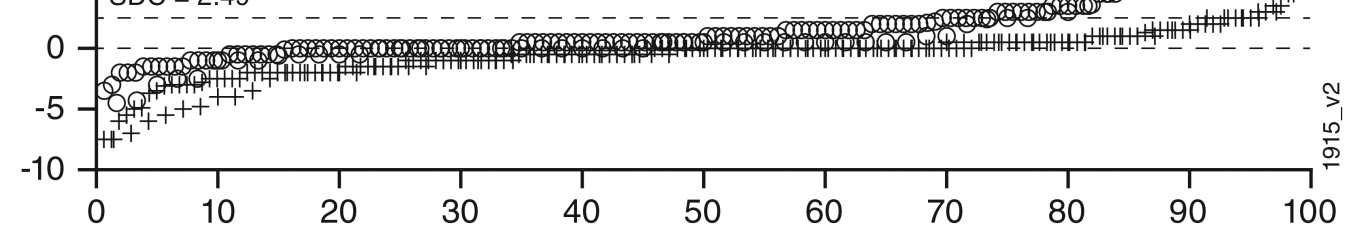

B

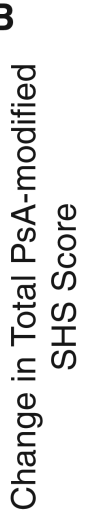

Cumulative Percentage

Patients with MTX Use at Baseline

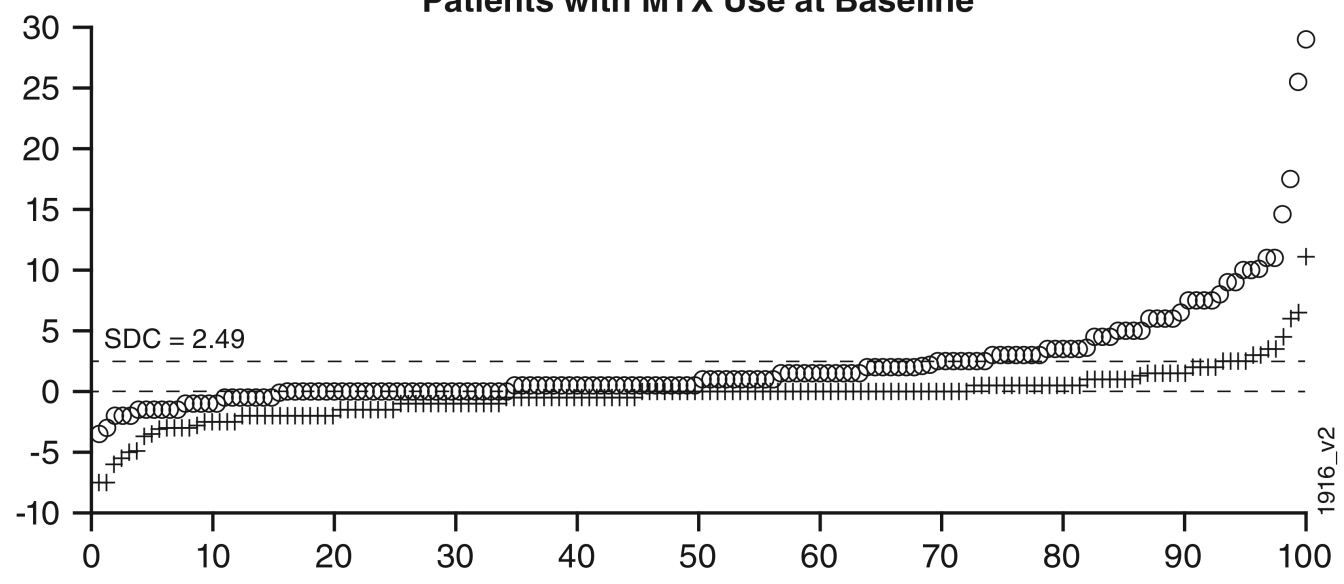

Cumulative Percentage

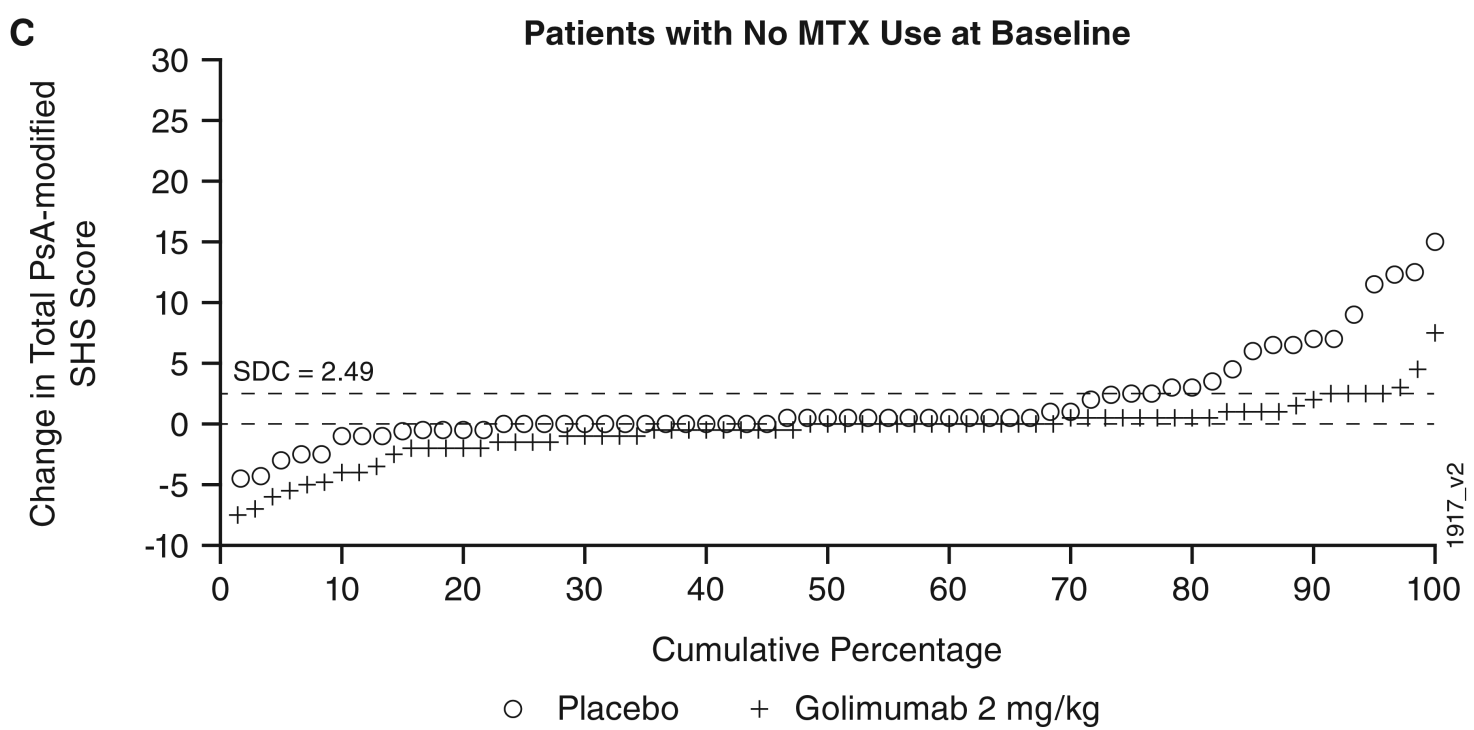

Figure 1. Cumulative probability plots of changes in total PsA-modified SvdH at Week 24 (full analysis set for structural damage endpoints) for (A*) all patients receiving IV treatment; (B) patients with MTX use at baseline; and (C) patients with no MTX use at baseline. *Panel A from Figure 2 of Kavanaugh A, et al. Safety and efficacy of intravenous golimumab in patients with active psoriatic arthritis: results through week twenty-four of the GO-VIBRANT study. Available from https://onlinelibrary.wiley.com/doi/full/10.1002/art.40226 and licensed under CC BY 2.0. IV: intravenous; MTX: methotrexate; PsA: psoriatic arthritis; SDC: smallest detectable change; SvdH and SHS: Sharp/van der Heijde score.

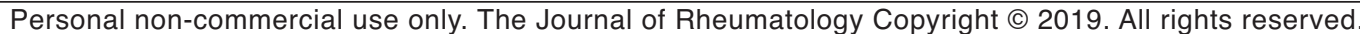


Table 3. Summary of mean (SD) change from baseline at Week 24 in PsA-modified SvdH (observed data) by treatment group and observed ACR response at Week 24.

\begin{tabular}{|c|c|c|}
\hline Response at Week 24 & $\begin{array}{c}\text { IV } \\
\text { Placebo }\end{array}$ & $\begin{array}{l}\text { IV Golimumab, } \\
2 \mathrm{mg} / \mathrm{kg}\end{array}$ \\
\hline \multicolumn{3}{|l|}{ ACR20 } \\
\hline Responder, $\mathrm{n}$ & 60 & 181 \\
\hline Change in total PsA-modified SvdH & $1.08(2.92)$ & $-0.60(2.10)$ \\
\hline $\mathrm{p}^{\mathrm{a}}$ & & $<0.001$ \\
\hline Nonresponder, $\mathrm{n}$ & 48 & 153 \\
\hline Change in total PsA-modified SvdH & $2.48(4.62)$ & $0.41(2.63)$ \\
\hline $\mathrm{p}^{\mathrm{a}}$ & & $<0.001$ \\
\hline \multicolumn{3}{|l|}{ ACR50 } \\
\hline Responder, $\mathrm{n}$ & 16 & 126 \\
\hline Change in total PsA-modified SvdH & $0.59(2.15)$ & $-0.56(2.20)$ \\
\hline $\mathrm{p}^{\mathrm{a}}$ & & 0.0413 \\
\hline Nonresponder, $\mathrm{n}$ & 198 & 103 \\
\hline Change in total PsA-modified SvdH & $2.21(4.35)$ & $-0.18(2.30)$ \\
\hline $\mathrm{p}^{\mathrm{a}}$ & & $<0.001$ \\
\hline \multicolumn{3}{|l|}{ ACR70 } \\
\hline Responder, $\mathrm{n}$ & 9 & 77 \\
\hline Change in total PsA-modified SvdH & $0.17(1.56)$ & $-0.95(2.17)$ \\
\hline $\mathrm{p}^{\mathrm{a}}$ & & 0.1017 \\
\hline Nonresponder, $\mathrm{n}$ & 206 & 153 \\
\hline Change in total PsA-modified SvdH & $2.17(4.30)$ & $-0.11(2.24)$ \\
\hline $\mathrm{p}^{\mathrm{a}}$ & & $<0.001$ \\
\hline
\end{tabular}

${ }^{\text {a }} \mathrm{P}$ value derived from an ANCOVA with van der Waerden rank test. ACR20/50/70: $\geq 20 / 50 / 70 \%$ improvement in American College of Rheumatology response criteria; IV: intravenous; PsA: psoriatic arthritis; SvdH: Sharp/van der Heijde score. from baseline $>0$ in the PsA-modified $\mathrm{SvdH}(28.3 \%$ vs $57.0 \%$, respectively; difference of $-28.7 \%$; $\mathrm{p}<0.001)$. Similar results were observed when patients were assessed for an increase in the PsA-modified SvdH $>0.5$ (18.6\% vs $41.8 \%$, respectively; difference of $-23.2 \%$; $<<0.001)$. Additionally, a smaller proportion of GOL- than placebo-treated patients demonstrated a change in the total PsA-modified SvdH exceeding the SDC at Week $24(8.0 \%$ vs $27.0 \%$, respectively; difference of $-19.0 \%$; $p<0.001$; Figure 3). Similar findings were observed when evaluating the component erosion and JSN scores (Figure 3).

\section{DISCUSSION}

PsA is a chronic inflammatory arthropathy than can be characterized by a range of symptoms, including arthritis, enthesitis, dactylitis, spondylitis, and skin and nail disease ${ }^{3,4}$. In about half of people with this disease, radiographic changes, including JSN, soft tissue changes, and new bone formation such as juxtaarticular periosteal reaction and ankylosis can lead to disability ${ }^{15,16}$. Biologic agents that inhibit TNF- $\alpha$ can significantly lessen PsA disease activity ${ }^{5}$.

In PsA, as in other conditions, patient preference plays a key role in choice of therapy. Factors such as route of administration (e.g., SC, IV, oral), dosing schedule, and other considerations can inform patients' preferences ${ }^{17}$. As reported previously, both SC and IV GOL rapidly and significantly improve clinical signs and symptoms of PsA and other health outcomes in patients with established and active PsA ${ }^{7,9}$.

In joints with scores $=0$ at baseline

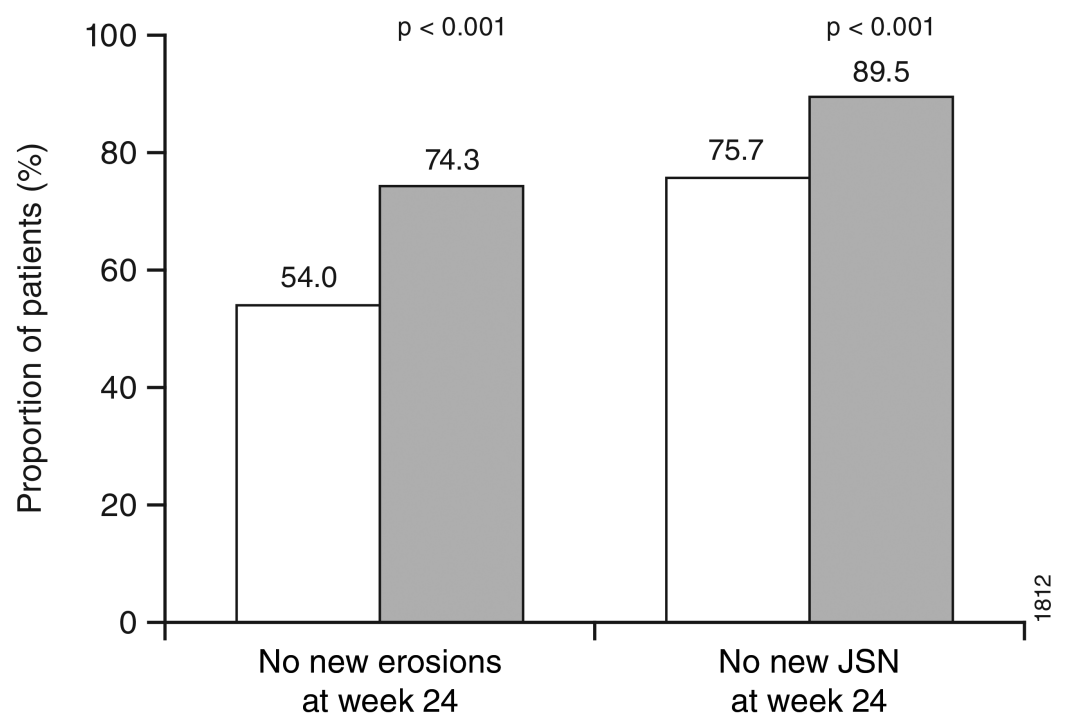

Placebo $(n=237)$

Golimumab 2 mg/kg ( $=237)$

Figure 2. Changes in PsA-modified SvdH at Week 24: proportions of patients receiving IV treatment with no new erosions or JSN in joints with score $=0$ at baseline (full analysis set for structural damage endpoints). IV: intravenous; JSN: joint space narrowing; PsA: psoriatic arthritis; SvdH: Sharp/van der Heijde score. 


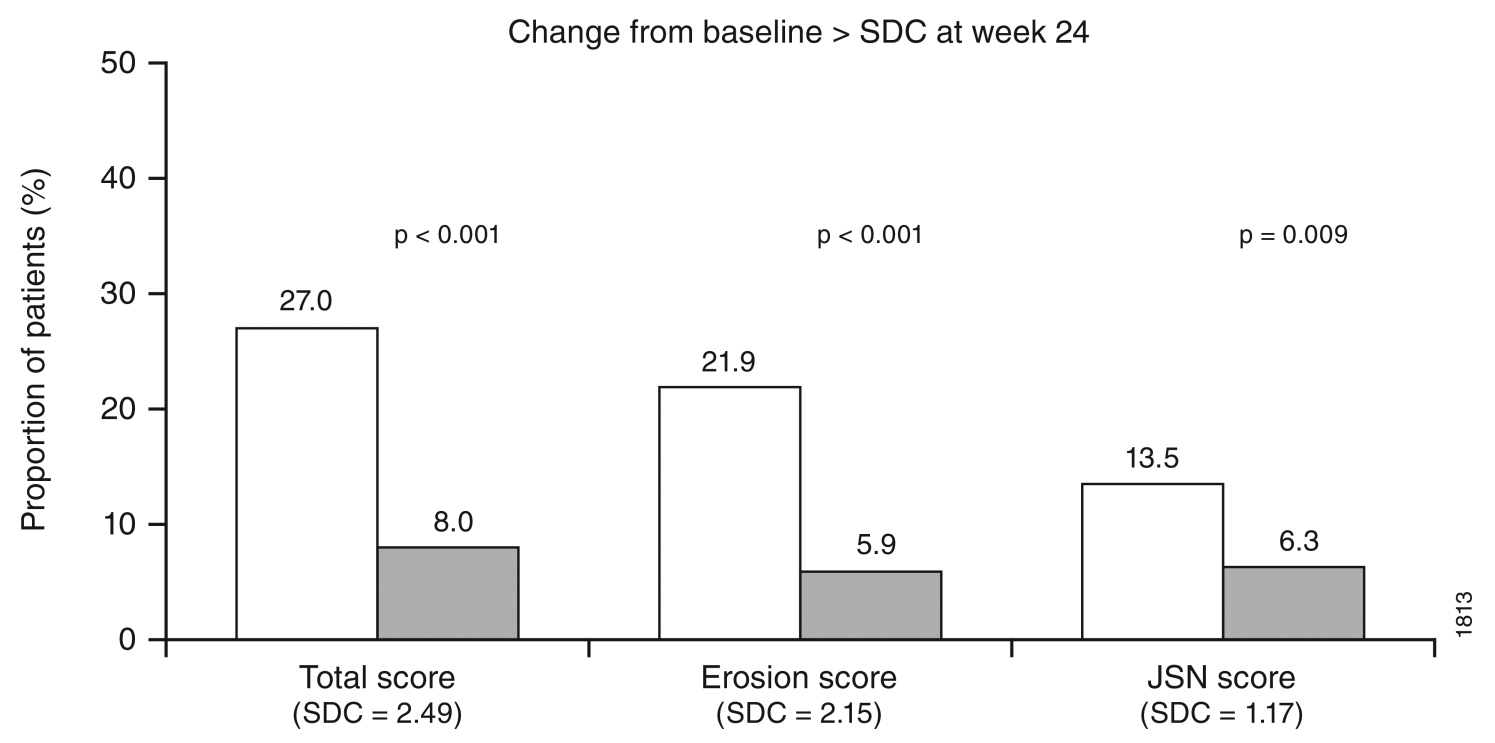

Placebo $(n=237)$

Golimumab $2 \mathrm{mg} / \mathrm{kg}(\mathrm{n}=237)$

Figure 3. Changes in PsA-modified SvdH at Week 24: proportions of patients receiving IV treatment with change exceeding the SDC for total, erosion, and JSN scores (full analysis set for structural damage endpoints). IV: intravenous; JSN: joint space narrowing; PsA: psoriatic arthritis; SDC: smallest detectable change; SvdH: Sharp/van der Heijde score.

Consistent with the inhibition of structural damage observed with $\mathrm{SC} \mathrm{GOL}^{8}$, radiographic data reported herein demonstrated significantly better inhibition of structural damage progression in IV GOL- compared with placebo-treated patients. GOL inhibited structural damage progression independent of its effects on clinical disease activity, as assessed by ACR20, ACR50, and ACR70 responses, in posthoc analyses. Of note, consistent results have previously been observed for patients with RA treated by means of TNF inhibition, with benefits in radiographic progression observed among patients not achieving clinical improvement $^{18}$. In PsA, it will be important to further evaluate the association between radiographic progression and disease activity with extended exposure to IV GOL as well as other biologic agents, including those with different mechanisms of action. Of course, it would not necessarily be indicated or prudent to continue any therapy in the absence of significant clinical benefit, even if there were to be inhibition of radiographic progression, because the longer-term implications of this are unknown.

Significant inhibition of structural damage progression in both components of the total PsA-modified SvdH (i.e., erosion and JSN scores) also was demonstrated with IV GOL relative to placebo. Findings obtained from 5 planned sensitivity analyses and baseline demographic and disease subgroup analyses were consistent and supported the efficacy of IV GOL in inhibiting radiographic progression. Results also were consistent for hands and feet when assessed individually and between patients with and without baseline use of MTX, NSAID, and oral low-dose corticosteroids.
Importantly, a smaller proportion of GOL- than placebo-treated patients demonstrated radiographic progression based on the SDC for the total PsA-modified SvdH, as well as for the individual erosion and JSN measurements. Uniform results were observed when evaluating changes from baseline of $>$ 0 or $>0.5$, further supporting the finding that fewer GOL-treated patients exhibited radiographic progression. Good agreement between the 2 central independent radiograph readers was observed for Week 24 change scores, with ICC coefficients of $0.64-0.73$ across the component and total change scores.

According to consensus findings from an international task force, the primary goal of treating individuals with PsA is to "maximize long-term health-related quality of life and social participation through control of signs and symptoms, prevention of structural damage, normalization or preservation of function, avoidance of toxicities, and minimization of comorbidities"19. Thus, it is noteworthy that IV GOL can effectively treat these diverse aspects of PsA, including inhibition of radiographic progression, which is particularly consequential for longer-term outcomes of patient function and disability ${ }^{20,21}$. Further analyses will extend radiographic evaluation of IV GOL in patients with PsA through 1 year to address a limitation of the current report (i.e., relatively short duration of followup in this chronic disease). The safety of IV GOL $2 \mathrm{mg} / \mathrm{kg}$ in these biologic-naive patients with active PsA was reported previously 9 .

IV GOL $2 \mathrm{mg} / \mathrm{kg}$ is significantly better than placebo in inhibiting progression of structural damage in patients with active PsA.

Personal non-commercial use only. The Journal of Rheumatology Copyright @ 2019 . All rights reserved. 


\section{ACKNOWLEDGMENT}

The authors thank Stephen Xu, MS, of Janssen Research \& Development LLC, for statistical support and Michelle L. Perate, MS, a professional medical writer funded by Janssen Scientific Affairs LLC, for writing and submission support.

\section{ONLINE SUPPLEMENT}

Supplementary material accompanies the online version of this article.

\section{REFERENCES}

1. Gladman DD, Shuckett R, Russell ML, Thorne JC, Schachter RK. Psoriatic arthritis (PsA) - an analysis of 220 patients. Q J Med 1987;62:127-41.

2. Torre Alonso JC, Rodriguez Perez A, Arribas Castrillo JM, Ballina Garcia J, Riestra Noriega JL, Lopez Larrea C. Psoriatic arthritis (PA): a clinical, immunological and radiological study of 180 patients. Br J Rheumatol 1991;30:245-50.

3. Ritchlin CT, Kavanaugh A, Gladman DD, Mease PJ, Helliwell P, Boehncke WH, et al; Group for Research and Assessment of Psoriasis and Psoriatic Arthritis (GRAPPA). Treatment recommendations for psoriatic arthritis. Ann Rheum Dis 2009;68:1387-94.

4. Gossec L, Smolen JS, Gaujoux-Viala C, Ash Z, Marzo-Ortega H, van der Heijde D, et al; European League Against Rheumatism. European League Against Rheumatism recommendations for the management of psoriatic arthritis with pharmacological therapies. Ann Rheum Dis 2012;71:4-12.

5. Mease PJ. Biologic therapy for psoriatic arthritis. Rheum Dis Clin N Am 2015;41:723-38.

6. Simponi ARIA Prescribing Information. Horsham, PA: Janssen Biotech Inc.; 2016.

7. Kavanaugh A, van der Heijde D, McInnes IB, Mease P, Krueger GG, Gladman DD, et al. Golimumab in psoriatic arthritis: one-year clinical efficacy, radiographic, and safety results from a phase III, randomized, placebo-controlled trial. Arthritis Rheumatol 2012;64:2504-17.

8. Kavanaugh A, van der Heijde D, Beutler A, Gladman D, Mease P, Krueger GG, et al. Radiographic progression of patients with psoriatic arthritis who achieve minimal disease activity in response to golimumab therapy: results through 5 years of a randomized, placebo-controlled study. Arthritis Care Res 2016;68:267-74.

9. Kavanaugh A, Husni ME, Harrison DD, Kim L, Lo KH, Leu JH, et al. Safety and efficacy of intravenous golimumab in patients with active psoriatic arthritis: results through week twenty-four of the GO-VIBRANT study. Arthritis Rheumatol 2017;69:2151-61.
10. Taylor W, Gladman D, Helliwell P, Marchesoni A, Mease P, Mielants H, et al; CASPAR Study Group. Classification criteria for psoriatic arthritis: development of new criteria from a large international study. Arthritis Rheumatol 2006;54:2665-73.

11. van der Heijde DM, van Leeuwen MA, van Riel PL, Koster AM, van 't Hof MA, van Rijswijk MH, et al. Biannual radiographic assessments of hands and feet in a three-year prospective followup of patients with early rheumatoid arthritis. Arthritis Rheumatol 1992;35:26-34.

12. van der Heijde D, Sharp J, Wassenberg S, Gladman DD. Psoriatic arthritis imaging: a review of scoring methods. Ann Rheum Dis 2005;64 Suppl 2:ii61-4.

13. Rubin DB. Multiple imputation for nonresponse in surveys. New York: John Wiley \& Sons; 2008.

14. Felson DT, Anderson JJ, Boers M, Bombardier C, Furst D, Goldsmith C, et al. American College of Rheumatology. Preliminary definition of improvement in rheumatoid arthritis. Arthritis Rheumatol 1995;38:727-35.

15. Day MS, Nam D, Goodman S, Su EP, Figgie M. Psoriatic arthritis. J Am Acad Orthop Surg 2012;20:28-37.

16. Schett G. Effects of inflammatory and anti-inflammatory cytokines on the bone. Eur J Clin Invest 2011;41:1361-6.

17. Elman SA, Weinblatt M, Merola JF. Targeted therapies for psoriatic arthritis: an update for the dermatologist. Semin Cutan Med Surg 2018;37:173-81.

18. Smolen JS, Han C, Bala M, Maini RN, Kalden JR, van der Heijde $\mathrm{D}$, et al; ATTRACT Study Group. Evidence of radiographic benefit of treatment with infliximab plus methotrexate in rheumatoid arthritis patients who had no clinical improvement: a detailed subanalysis of data from the anti-tumor necrosis factor trial in rheumatoid arthritis with concomitant therapy study. Arthritis Rheum 2005;52:1020-30.

19. Smolen JS, Braun J, Dougados M, Emery P, FitzGerald O, Helliwell $\mathrm{P}$, et al. Treating spondyloarthritis, including ankylosing spondylitis and psoriatic arthritis, to target: recommendations of an international task force. Ann Rheum Dis 2014;73:6-16.

20. Husted JA, Tom BD, Farewell VT, Schentag CT, Gladman DD. Description and prediction of physical functional disability in psoriatic arthritis: a longitudinal analysis using a Markov model approach. Arthritis Rheumatol 2005;53:404-9.

21. Leung YY, Ho KW, Li EK, Li M, Kwok LW, Wong PC, et al. Predictors of functional deterioration in Chinese patients with psoriatic arthritis: a longitudinal study. BMC Musculoskelet Disord 2014;15:284. 